\title{
Exploration and practice for engineering innovative talents training based on project-driven
}

Yishen Xu, Qingsong Lv, Yan Ye, Maocheng Wu, Jihua Gu

Yishen Xu, Qingsong Lv, Yan Ye, Maocheng Wu, Jihua Gu, "Exploration and practice for engineering innovative talents training based on project-driven," Proc. SPIE 10452, 14th Conference on Education and Training in Optics and Photonics: ETOP 2017, 1045244 (16 August 2017); doi: 10.1117/12.2266487

SPIE Event: 14th Conference on Education and Training in Optics and Photonics, ETOP 2017, 2017, Hangzhou, China 


\title{
Exploration and practice for engineering innovative talents' training based on project-driven
}

\author{
Yishen Xu, Qingsong Lv, Yan Ye, Maocheng Wu*, Jihua Gu \\ College of Physics, Optoelectronics and Energy, Soochow University, Suzhou 215006, China
}

\begin{abstract}
As one of the "excellent engineer education program" of the Ministry of Education and one of the characteristic majors of Jiangsu Province, the major of optoelectronic information science and engineering in Soochow University has a long history and distinctive features. In recent years, aiming to the talents training objective of "broad foundation, practiceoriented, to be creative", education and teaching reforms have been carried out, which emphasize basis of theoretical teaching, carrier of practical training, promotion of projects and discussion, and development of second class. By optimizing the teaching contents and course system of the theoretical courses, the engineering innovative talents training mode based on the project-driven has been implemented with playing a practical training carrier role and overall managing the second class teaching for cultivating students' innovative spirit and practical ability. Meanwhile, the evaluation mechanism of the students' comprehensive performance mainly based on "scores of theory test" is being gradually changed, and the activities such as scientific research, discipline competitions and social practices are playing an increasing important role in the students' comprehensive assessment. The produced achievements show that the proposed training model based on project-driven could stimulate the students' enthusiasm and initiative to participate in research activities and promote the training of students' ability of engineering practice and consciousness of innovation.
\end{abstract}

Keywords: reform of training model, talents cultivation, opening teaching, special research

\section{INTRODUCTION}

At present, there are many problems, such as "emphasizing theory, neglecting practice", the homogenization of classroom teaching, and the formalization of experimental teaching in the professional training mode of optoelectronics majors in most of the domestic universities ${ }^{[1]}$. Except for the spirit of innovation, unity and cooperation, the innovative talents meeting the requirements of social development should also have a strong practical ability of operation, ability of engineering design, ability of comprehensive application, ability of scientific research and ability of analyzing and solving the problem independently, but all of these abilities are required to combine theoretical teaching and engineering practice teaching ${ }^{[2]}$.

In recent years, aiming to the talents training objective of "broad foundation, practice-oriented, to be creative", and combining the inherent requirements of education for the cultivation of talents' knowledge, quality and comprehensive ability, and the actual needs of the talents of optoelectronic information industry, by making full use of the "excellent engineer education program" of the Ministry of Education and many years' achievements of our education and research, education and teaching reforms in Soochow University have been carried out, which emphasized basis of theoretical teaching, carrier of practical training, promotion of projects and discussion, and development of second class. In addition, by optimizing the teaching contents and course system of the theoretical courses, the engineering innovative talents training mode based on the project-driven has been implemented with playing a practical training carrier role and overall managing the second class teaching for cultivating students' innovative spirit and practical ability. Beyond that, the evaluation mechanism of the students' comprehensive performance mainly based on "scores of theory test" is being gradually changed, and the activities such as scientific research, discipline competitions and social practices are playing an increasing important role in the students' comprehensive assessment.

By means of the project-based curriculum teaching of the course "special research (prototype)", the recent years' exploration and practices in the cultivation of engineering innovation talents for the photoelectric information science and engineering major of Soochow University are introduced in this paper.

*wumc@suda.edu.cn 


\section{CURRICULUM DESIGN}

Adhering to the educational concept of "opening teaching", taking the student as the main body and the project research as the main line, the course of "special research (prototype)" was offered to provoke the students' learning initiative through the reform of the original assessment requirements, examination content and evaluation criteria, and meanwhile taking into account the fair and reasonable assessment of the course. In addition, considering the richness and diversity of the required professional knowledge, the students should complete the study of professional basic courses, such as analog circuits, digital circuits, $\mathrm{C}$ language programming and theory and interface technology of single chip microcomputer in advance.

\subsection{Purposes and significance}

The purposes of this course are mainly listed as the following points. First of all, the students are trained to learn the basic idea of optoelectronic system design and basic methods, and master all kinds of design tools. Secondly, the project practice could give full play to the personality of students and deepen their understanding of optical and circuit-related knowledge. Finally, by guiding students to design, install and debug the actual photoelectric systems, the comprehensive abilities of using theoretical knowledge to analyze and solve problem independently are trained. During this process, the scientific rigorous style and good habits would be formed gradually.

\subsection{Specific goals}

Through the study of this course, the students' ability could be improved in the following areas: learning the general design methods of photoelectric systems, with the initial independent design capabilities; mastering the ability to access technical datasheets and manuals; selecting the design scheme, circuit and device reasonably; mastering the installation of photoelectric systems wiring, debugging troubleshooting, and other basic skills; having the ability of schematic design, PCB design and circuit simulation, with the design capabilities of photoelectric sensing circuit, analog signal processing circuit, as well as digital circuits and microprocessor circuit; having the ability of application programming and debugging; writing a specification design report and so on.

\subsection{Topic requirements}

First of all, the topic should be able to combine optics and circuit, including photoelectric sensor, analog circuit design, digital circuit design, microprocessor, simulation and application programming, and PCB design, circuit welding and debugging. Secondly, the topic should be suitable for practical teaching and inspiration innovation, and the topic content should not be too simple, the difficulty should be moderate, meanwhile paying attention to the topics' progressiveness, comprehensiveness and practicality. In addition, the selected topics should be combined with the actual situation of the engineering, and have a certain practical value. Furthermore, the prototype should have a complete function relatively.

\subsection{Teaching process}

Firstly, the teacher introduces the contents, requirements, arrangements, assessment methods and precautions of the course, and instructs the necessary background, relevant knowledge and principle, in order to help the students clearly understand the requirements of functionality and performance about the designed system, the general design methods of photovoltaic systems, the installation process, and the commissioning methods. Then, students will review the relevant information in groups, and complete the overall system design in two weeks, including the system program demonstration and comparison process, functional realization of the technical route and schematic diagram drawing of the designed system. After that, the teacher examines that whether the designed report is standardized and whether the designed scheme is reasonable, correct and feasible. Once the designed system scheme has passed through the teacher's check and assessment, the team members need completing the component selection, the parameters calculation, the design of schematic diagram within the next two weeks, and making an agreement with the instructor again. And after these validated steps, the project team can proceed with PCB design and production, application programming, system prototype testing and writing summary report and so on. In the traditional experimental courses, some problems that the students do not need to concern with, such as how to choose the experimental components, how to determine the key parameters, how to buy the devices, which channel can be purchased and so on, are all required to be solved by the students themselves. Thus, the experimental subject design and research work could be ensured to carry out smoothly. During the process of prototype's hardware and software debugging and troubleshooting, the teacher will give appropriate guidance and supervision, guide students to complete their project successfully, meanwhile take into account cultivating students' independent ability and completing the design tasks within the specified time. 


\subsection{Assessment methods and performance evaluation}

According to the requirements of the course assessment, the project team needs completing the system prototype before one week at the end of the semester, and submitting the system schematic diagram, PCB file, application source code and designed report. At the end of the semester, the project team needs to conduct live demonstrations and present an oral defense for their work, while listening to the advice and suggestions from the teacher and other classmates. For this course, the total score of a certain student is mainly composed of four parts: the comprehensive performance of the group prototype, the accomplishment of the individual task, the performance of the mutual evaluation in the group and the overall scores of project defense, as shown in Figure 1.

\section{Personal total score}

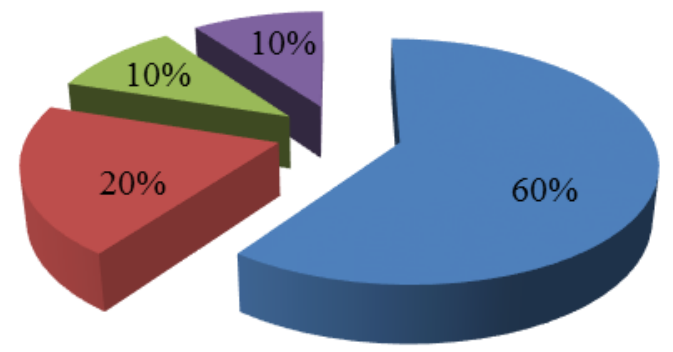

- Comprehensive performance of the group works

- Accomplishment of the individual task

- Performance of the mutual evaluation in the group - Overall scores of project defense

Figure 1. Total score of a certain student.

The instructor will give $60 \%$ of the total score for the group prototype based on the schematics, the PCB file, the source code, the work report and the live demonstration (same scores for one group); The tutor gives $20 \%$ of the total score of the individual in combination with the individual division of labor and the completion of the responsible part of the material; anonymous assessment score from other members of the same group accounts for $10 \%$ of the individual total score; and the overall performance of the project defense accounts for the last $10 \%$ of the individual total score. And if the average score given by other members of the same group is unqualified, the certain student's total score is unqualified.

\section{CURRICULUM PRACTICE}

In the implementation of the course, each group often consists of three to four members. In the stage of project selection, the mode of "teacher recommended subject or student independent topic" is adopted to fully mobilize the enthusiasm of students, which can not only make up for the deficiency of the students in the experience of the project, but also give full play to the imagination and innovation consciousness of the students. Besides, the project team needs to complete the selection of the project subject, the selection of the team leader and the division of the task of the team members in the first week of the course, and submit them to the instructor for confirmation.

Table 1. List of partial special research topics in recent three years.

\begin{tabular}{|c|l|}
\hline Sequence number & \multicolumn{1}{c|}{ Title } \\
\hline 1 & Photovoltaic charging controller with the function of MPPT \\
\hline 2 & Intelligent controller of energy-saving street lamp \\
\hline 3 & Photoelectric detection smart car \\
\hline 4 & Intelligent micro-ohmmeter based on four-line method \\
\hline 5 & Intelligent home lighting system based LED \\
\hline 6 & Automotive micro-inverter based on TL494 \\
\hline 7 & LED lighting system based on capacitive touch and infrared wireless remote control \\
\hline 8 & Carbon dioxide detection system based on IR absorption principle \\
\hline
\end{tabular}

The topic of the course for the past three years is shown in Table 1. Part of the designed prototypes and the project defense scene are shown in Fig. 2 to Fig.5. 


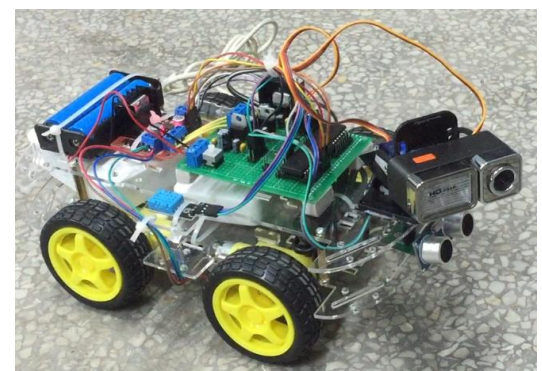

Figure 2. Photoelectric detection smart car.

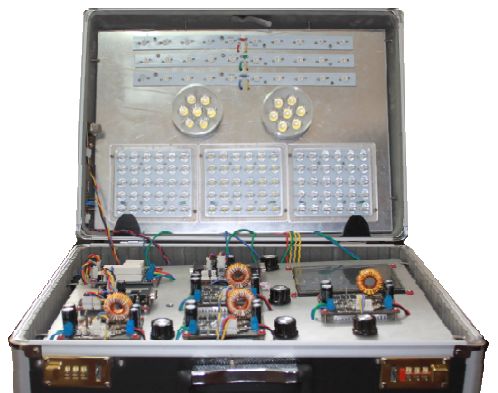

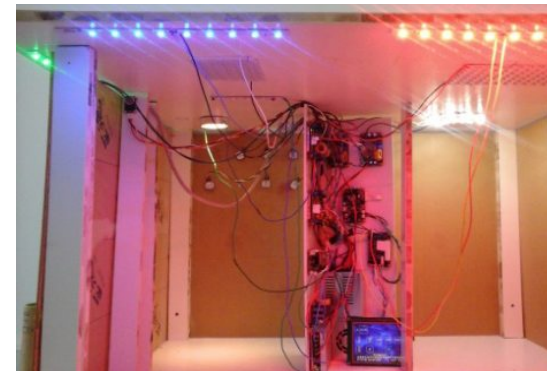

Figure 3. Intelligent home scene lighting system.

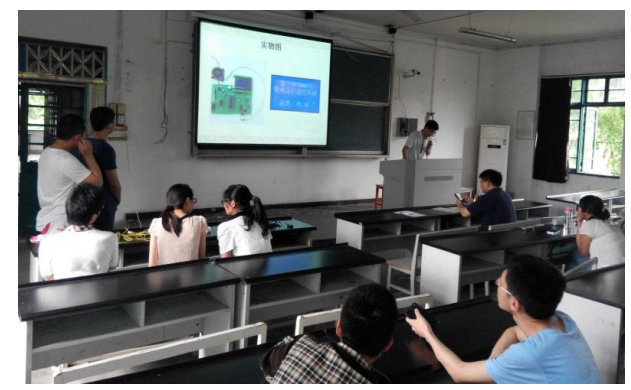

Figure 4. LED lighting system based on capacitive touch and infrared wireless remote control. Figure 5. Project defense scene.

\section{CONCLUSIONS}

The produced achievements show that the proposed training model based on project-driven could provoke the students' enthusiasm and initiative to participate in research activities and promote the training of students' ability of engineering practice and consciousness of innovation. In the spare time, many students will spontaneously come into the laboratory for the design and discussion of their project and the practical problems encountered in the process of project research, and actively think to explore the feasible solutions. Thus, some drawbacks of traditional experimental teaching mode have been effectively solved. Moreover, after the first project baptism, students began to realize that they have the ability in solving the practical problems in daily life, which will greatly enhance their professional self-confidence. Meanwhile, the proposed training mode which takes the students as the main body, the task group as the unit, and the project as the main line, could also establish a solid foundation for their future development.

\section{ACKNOWLEDGEMENTS}

This work was supported by 2015 teaching reform research project in higher education of Soochow University (youth project) and by $3^{\text {th }}$ teaching research project about hot and difficult issues in higher education for specialty in optoelectronic information science and engineering of the Chinese colleges and universities.

\section{REFERENCES}

[1] Cun, Y. L., Zhou, Q., Chen, Z. G., "The new 'project + contest + certification' talents training mode of electronics specialty in local universities," The Guide of Science \& Education, 65-67 (2015).

[2] Liu, Y. F., Li, Q., Guo, S. L., and Xu, J., "Developing EDA integrated experimental platform and cultivating students' ability on engineering education," Research and Exploration in Laboratory, Vol. 26, No. 8, 63-65 (2007).

[3] Pang, H., "Discussion and practice on the teaching reform of 'electric circuit analysis' course," China Electric Power Education, 58-59 (2009).

[4] Liu, J. C., Mao, J. B., Yang, M. W., "Exploration and practice of subject construction of electronic science and technology," Journal of Hefei University of Technology (Social Sciences), Vol. 22, No. 6, 138-141 (2008). 